\title{
Adsorption Performance of La(III) and Y(III) on Orange Peel: Impact of Experimental Variables, Isotherms, and Kinetics
}

\author{
Li Liu $(\mathbb{D}$, Yunzhang Rao, Changshun Tian $(\mathbb{D}$, Tao Huang, Jiacheng Lu, Meidao Zhang, \\ and Min Han \\ School of Resources and Environment Engineering, Jiangxi University of Science and Technology, Ganzhou 341000, China \\ Correspondence should be addressed to Changshun Tian; 9320090329@jxust.edu.cn
}

Received 5 June 2021; Revised 18 August 2021; Accepted 4 September 2021; Published 21 September 2021

Academic Editor: Daniel Schwantes

Copyright ( $92021 \mathrm{Li} \mathrm{Liu} \mathrm{et} \mathrm{al.} \mathrm{This} \mathrm{is} \mathrm{an} \mathrm{open} \mathrm{access} \mathrm{article} \mathrm{distributed} \mathrm{under} \mathrm{the} \mathrm{Creative} \mathrm{Commons} \mathrm{Attribution} \mathrm{License,} \mathrm{which}$ permits unrestricted use, distribution, and reproduction in any medium, provided the original work is properly cited.

\begin{abstract}
To alleviate the environmental problem associated with rare earth wastewater, this research applied waste orange peel (OP) for the adsorption of $\mathrm{La}(\mathrm{III})$ and $\mathrm{Y}$ (III) from aqueous solution. The adsorption properties of orange peel are characterized using scanning electron microscopy (SEM) and Fourier transform infrared spectroscopy (FTIR), and the participation of hydroxyl and other oxygen-containing groups that promote the physical-chemical interaction is verified. Batch adsorption results suggest that orange peel possesses a satisfactory adsorption performance for $\mathrm{La}(\mathrm{III})$ and $\mathrm{Y}(\mathrm{III})$. The optimal adsorption conditions were obtained at $\mathrm{pH}$ of 6 , temperature of $40^{\circ} \mathrm{C}$, appropriate dosage of $2 \mathrm{~g} / \mathrm{L}$ and $3 \mathrm{~g} / \mathrm{L}$, contact time of $30 \mathrm{~min}$, and initial ion concentration of $32 \mathrm{mg} / \mathrm{L}$. Under the same condition, adsorption performance of $\mathrm{La}(\mathrm{III})$ is better than that of $\mathrm{Y}(\mathrm{III})$. The experimental data is well fitted by the Langmuir isotherm model with correlation coefficient $\left(R^{2}\right)>0.9$ and the minimum standard error values. Equilibrium results show that Langmuir monolayer adsorption capacity of $\mathrm{La}$ (III) and Y(III) onto orange peel is up to 37.61 and $31.10 \mathrm{mg} / \mathrm{g}$. The fitting results of kinetics prove that the adsorption process of La(III) and Y(III) follows the pseudosecond-order model. Thus, natural orange peel as a recyclable biosorbent has potential economic and applicative benefits to remove $\mathrm{La}(\mathrm{III})$ and $\mathrm{Y}(\mathrm{III})$ from aqueous solutions.
\end{abstract}

\section{Introduction}

Ion-adsorbed earth ore is one of the most crucial mineral resources in the world. It is increasingly frequent to generate massive volumes of rare earth wastewater on account of continuous mining and smelting $[1,2]$. Contaminated water from a mine in southern Jiangxi was measured that contained various rare earth elements (REEs), especially the higher concentrations of lanthanum and yttrium [3]. Slightly toxic REEs will accumulate once into living organisms and cannot be metabolized coupled with chronic ingestion, leading to the detrimental ecosystems and human health $[4,5]$.

The biosorption method is widely applied in the beneficiation and recovery of REEs $[6,7]$ by virtue of its advantages such as low cost, easy availability, high efficiency, and ecofriendliness [8]. For the porous surface and abundant adsorption functional groups with strong binding ability containing a carboxyl group, hydroxyl group, and amide group [9], orange peel (OP) is an exemplary candidate to deploy the adsorption technology for the mitigation of wastewater pollution; their biosorption studies have been mainly focused on heavy metals [10], organic drug [11], toxic oxyanions [12], and dyeing [13] wastewater. Nevertheless, there are a few reports concerning rare earth wastewater remediation $[14,15]$. The majority of studies have focused on modifying with OP to improve the adsorption capacity, and the modification methods mainly include acid [16], alkali [17], salt [18], structure [19], carbonization [20], organic solvents [21], and compound modification [22]. The whole preparation process of modified OP is shown in Figure 1. In the complex operating process, large numbers of chemical reagents and distilled water are consumed for repeated immersion and washing. Furthermore, the biological structure of OP is easily destroyed [23], which is challenging to ensure the stability of adsorption performance and reuse. Thereby, the disadvantages of time consuming 


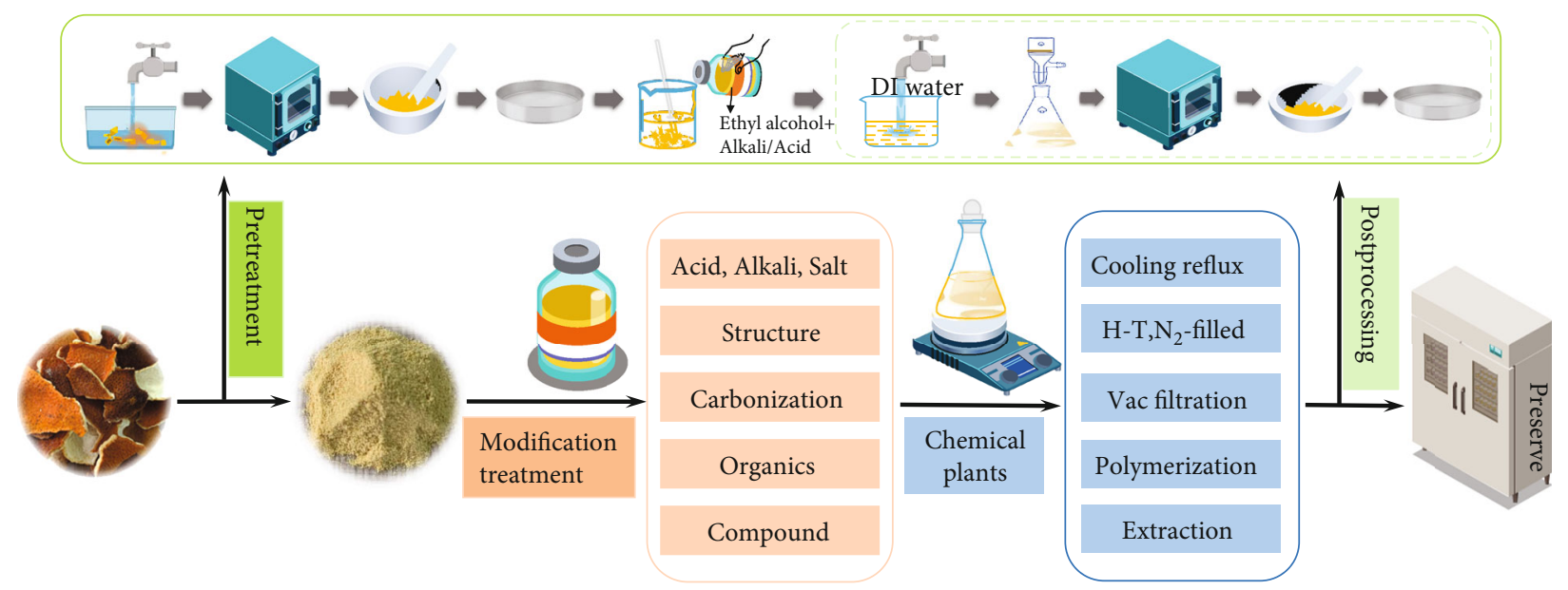

Figure 1: Preparation steps of modified OP.

and low yield indicate that the modification method is not advisable under certain conditions. Feng et al. [24, 25] obtained final modified OP products after undergoing multistep operation with much ethanol, $\mathrm{NaOH}$, and other modifiers to soak for more than $20 \mathrm{~h}$. Zhang et al. [26] studied the effects of activators by preparing activated carbon from citrus peel residue, and the yield was only about $37 \%$. Similarly, Xie et al. [27] applied OP to prepare activated carbon with the highest yield of 50.9\%. In addition, when it comes to organic modification, given the deficiency of biodegradability for some typical organic solvents like thioglycolic acid, formaldehyde acrylamide, and others, which brings about hazard of toxic substances and the whole process costs elevated.

In view of this, the adsorption properties of $\mathrm{La}(\mathrm{III})$ and Y(III) ions onto unmodified OP from aqueous solutions are investigated with characterization methods and varying conditions. This study is aimed at moderating rare earth wastewater pollution and addressing agricultural waste disposal, so as to provide theoretical and practical guidance for the application of OP in rare earth wastewater treatment.

\section{Materials and Methods}

2.1. Adsorbent Preparation. Orange peel was collected from an orchard in Ganzhou City, China. The peels were rinsed repeatedly without removing white pith, after which they were air dried and later oven dried at $65^{\circ} \mathrm{C}$ for constant weight. The dried peels were further ground into fine powder and sieved with particle size in the range of 125 to $150 \mu \mathrm{m}$. This powder was stored in PVC plastic bag for standby application. All chemicals used were of analytical grade. The $\mathrm{pH}$ was adjusted by adding either $\mathrm{NaOH}$ or $\mathrm{HCl}$. Rare earth stock solutions of $5 \mathrm{~g} / \mathrm{L}$ were prepared with lanthanum(III) sulfate octahydrate (99.99\% La) and yttrium(III) sulfate octahydrate (99.99\% Y) and diluted to desired concentration.

2.2. Characterization of the Prepared Adsorbent. A scanning electron microscope (SEM) (XL30 W/TMP, Philips, Netherlands) is used to assess the changes of the OP surface mor- phology before and after adsorption. The spectra of the adsorbents are recorded by the Nicolet Fourier infrared spectrometer (FTIR) in the wavelength range of 400$4000 \mathrm{~cm}^{-1}$, which can identify the affinity between the various functional groups of $\mathrm{OP}$ and that adsorption process for $\mathrm{La}(\mathrm{III})$ and $\mathrm{Y}(\mathrm{III})$.

2.3. Batch Adsorption Experiments. Adsorption experiments were performed in a set of $250 \mathrm{~mL}$ stoppered conical flasks by adding $0.15 \mathrm{~g}$ OP to $100 \mathrm{~mL}$ rare earth solutions with initial concentration of $32 \mathrm{mg} / \mathrm{L}$ at $\mathrm{pH}$, and then, the solution was stirred for $120 \mathrm{~min}$ in constant speed agitators at room temperature. Selectivity adsorption experiments at different parameters were carried out to establish the optimal adsorption conditions. The effects of different experimental conditions on adsorption of OP were investigated by varying initial $\mathrm{pH}$ from 2 to 7 , dosage of OP from $0.05 \mathrm{~g}$ to $0.5 \mathrm{~g} / 100 \mathrm{~mL}$, and repeating experiment between 20 and $50^{\circ} \mathrm{C}$. The various initial concentration of rare earth ions ranged from 5 to $100 \mathrm{mg} / \mathrm{L}$ for isothermal adsorption study, and the kinetic study was carried out by varying contact time between 2.5 and $120 \mathrm{~min}$. After reaching the preset contact time, a small number of supernatant solutions were filtered immediately.

The residual concentration of rare earth ions after adsorption is detected by spectrophotometer (UV-5100). The adsorption capacity $\left(q_{\mathrm{e}}, \mathrm{mg} / \mathrm{g}\right)$ and adsorption rate $(\eta$, $\%)$ are calculated by the following equations:

$$
\begin{gathered}
q_{\mathrm{e}}=\frac{\left(C_{0}-C_{\mathrm{e}}\right) V}{M}, \\
\eta=\left[\frac{C_{0}-C_{e}}{C_{0}}\right] \cdot 100,
\end{gathered}
$$

where $C_{0}$ and $C_{\mathrm{e}}(\mathrm{mg} / \mathrm{L})$ are the initial and final or equilibrium $\mathrm{REE}$ concentration in solution, respectively; $V$ (L) denotes the volume of solution; and $M(\mathrm{~g})$ refers to the mass of OP powder. 


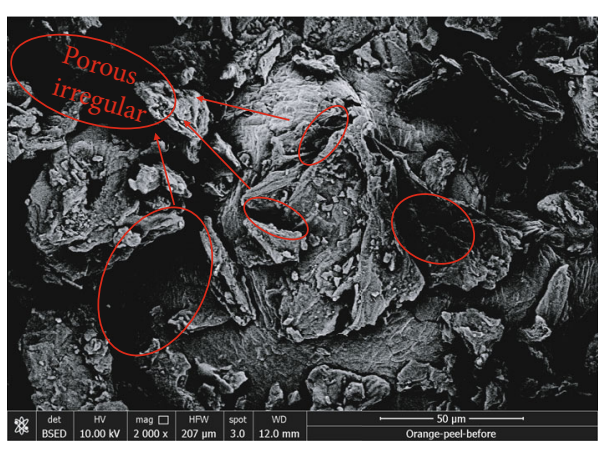

(a) $\mathrm{OP}$

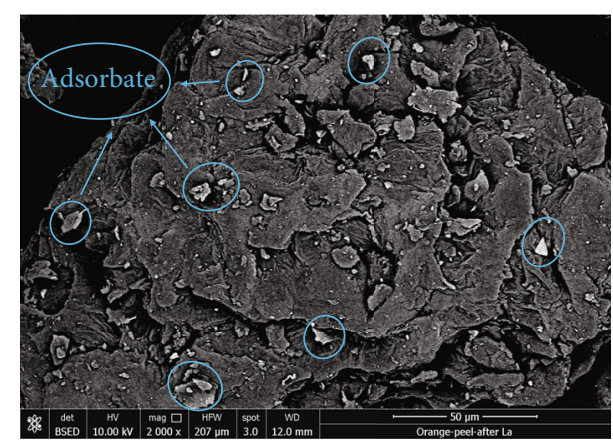

(b) OP-La(III)

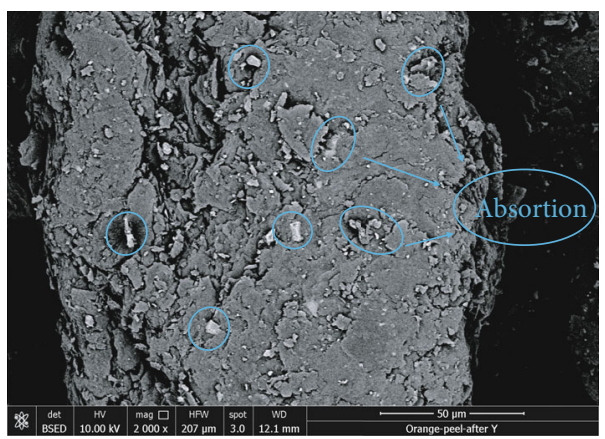

(c) OP-Y(III)

FIgURE 2: SEM images of OP before (a) and after La(III) (b) and Y(III) (c) adsorption.

\section{Results and Discussion}

\subsection{Morphology and Functional Groups of $O P$}

3.1.1. SEM Analysis. Figure 2 displays difference of OP surface structure. Before adsorption, OP embodied a loose and uneven porous structure, which provides plenty of effective sites for the adsorption of La(III) and Y(III). According to the principle of backscattered electron imaging, the microregions with high average atomic numbers in the sample are brighter on the image. Hence, it can be explained that luminous points of images (Figures 2(b) and 2(c)) are the adsorptive distributions of $\mathrm{La}$ (III) and Y(III) on the OP surface. The phenomenon reveals that the pore structure of OP is conducive to physical adsorption, and the charge aggregation of particle surface can be illustrated by the outersphere mutual acting (electrostatic) and the surface nucleation of REEs microcrystals in the adsorption process $[9,28]$.

3.1.2. FTIR Analysis. As shown in Figure 3, the participation of diverse functional groups is proved by FTIR spectra of OP before and after adsorption. The peaks appear at $3428.30 \mathrm{~cm}^{-1}$, identifying as $\mathrm{O}-\mathrm{H}$ vibrations that originate from the hydroxyl groups of alcohols, phenols, and carboxylic acids on the adsorbent surface [29]. The peak at $3099.87 \mathrm{~cm}^{-1}$ attributed to $\mathrm{C}-\mathrm{H}$ stretching of the alkane groups [30], and the bimodality peaks near $2731.11 \mathrm{~cm}^{-1}$ represent the stretching of symmetric and asymmetric $-\mathrm{CH}$ bond from the aldehyde group [31]. The triple bond and cumulative double bond stretching including the deformation of carbon occurs in several peaks between $2393.93 \mathrm{~cm}^{-1}$ and $2068.50 \mathrm{~cm}^{-1}$. The prominent peak at
$1757.36 \mathrm{~cm}^{-1}$ reflects $\mathrm{C}=\mathrm{O}$ stretching of the nonionized carboxyl groups, which can be associated to organic compounds in OP that contain the dimer form of carboxylic acids, carboxylic esters, ketones, or amides [19]. The peaks at $823.94 \mathrm{~cm}^{-1}$ and $708.71 \mathrm{~cm}^{-1}$ are assigned to $-\mathrm{CH}$ out-of-plane bending vibration on the aromatic rings [32]. Overall, these functional groups are derived from main components such as pectin, hemicellulose, and lignin [18].

The negligible differences of the OP spectral band before and after adsorption imply that the functional groups remain intact [33]. This is indicative of involvement of ion exchange or surface complexation process. Small range shifts of the peak position indicate that the hydroxyl, carboxyl, and carbonyl groups on the surface of OP played a critical role [30]. It is further supported by the reduction of vibrational intensity [33]. These notions are consistent with the previous finding about the adsorption of metals onto OP [30].

\subsection{Batch Adsorption}

3.2.1. Effect of Initial $\mathrm{pH}$. The solution $\mathrm{pH}$ has been identified as the significant control factor that impacts the adsorption process [34]. As can be seen in Figure 4, the adsorption rate first increases and then decreases with the $\mathrm{pH}$ rising from 2.0 to 7.0. The maximum adsorption rates achieved at $\mathrm{pH}$ of 6 were $96.99 \%$ and $96.84 \%$ for La(III) and Y(III), respectively. Further experiments were carried out at $\mathrm{pH} 6$, which is in agreement with the optimum removal of $\mathrm{Cd}(\mathrm{II})$ ion by OP at $\mathrm{pH} 6$ as well [30].

The adsorption of $\mathrm{La}$ (III) and Y(III) onto OP is intimately dependent on the initial $\mathrm{pH}$ that affects the both 


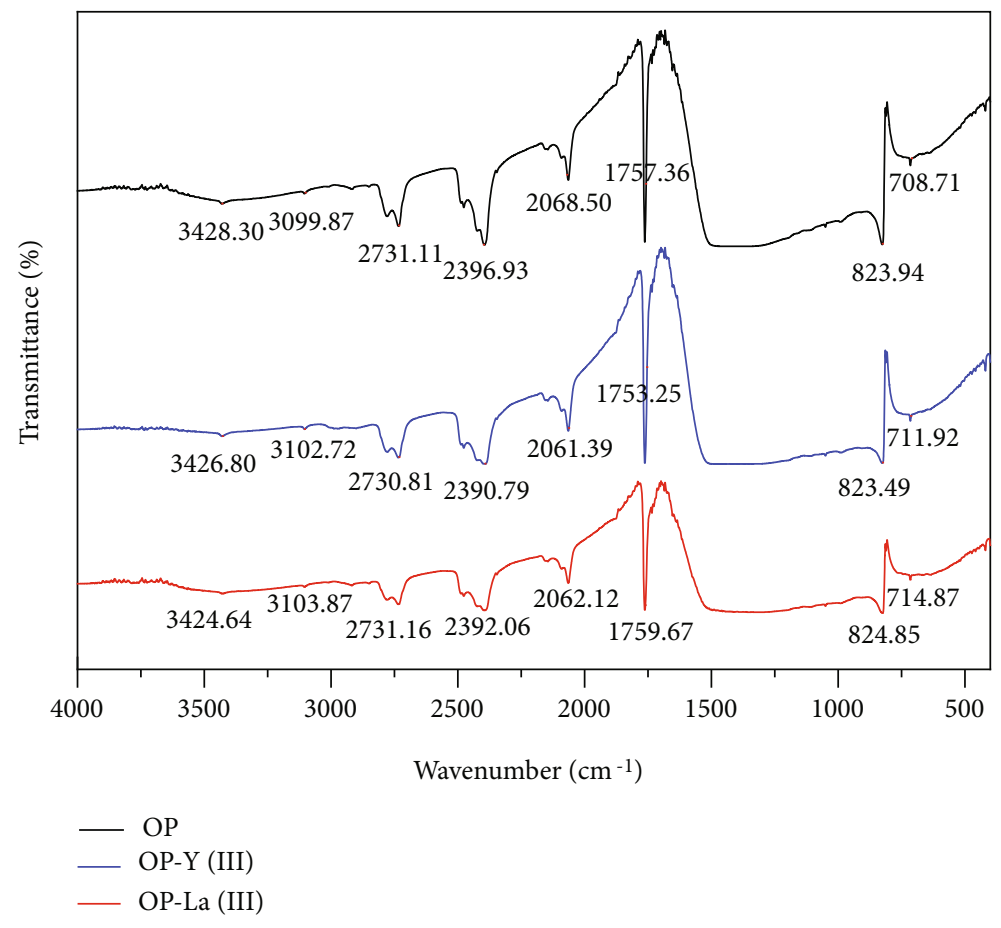

FIgURE 3: FTIR spectra of OP before and after adsorption for La(III) and Y(III).

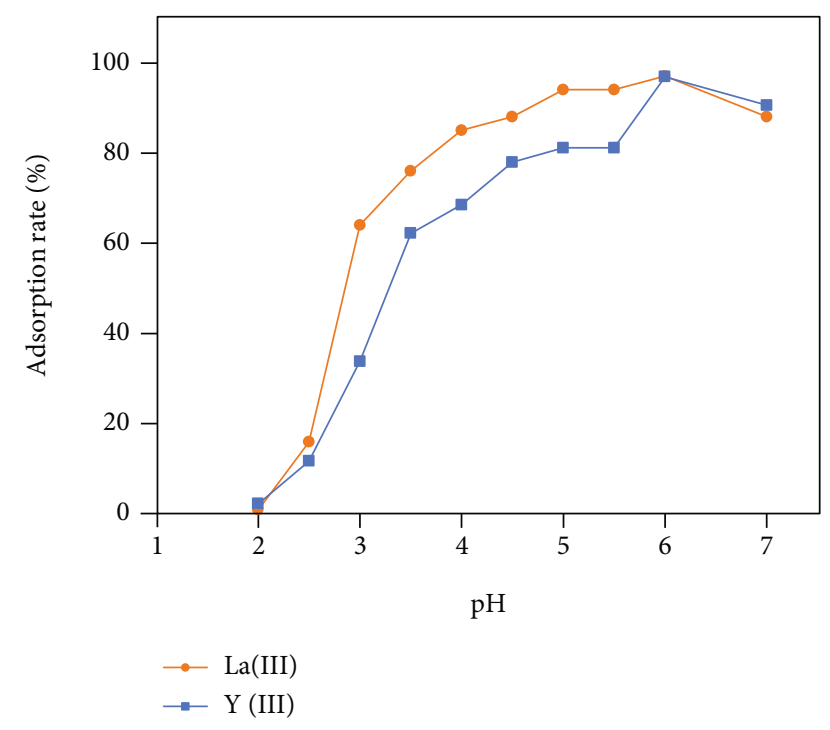

FIGURE 4: Effect of initial $\mathrm{pH}$ on the adsorption of $\mathrm{La}(\mathrm{III})$ and $\mathrm{Y}(\mathrm{III})$ by OP (room temperature, $C_{0}=32 \mathrm{mg} / \mathrm{L}, S / L=0.15 \mathrm{~g} / 100 \mathrm{~mL}, t=2 \mathrm{~h}$ ).

metal ion existing speciation and adsorbent surface charge [30]. Additionally, $\mathrm{H}^{+}$itself has strong competitive ability for adsorption sites [35]. Lower $\mathrm{pH}$ is considered to be a highly acidic medium that allows more protons to protonate active groups. Concurrently, the positive charge regions on OP and the rivalry for adsorption sites between excess $\mathrm{H}^{+}$ and two rare earth ions lead to lower adsorption rates [30]. With elevated $\mathrm{pH}$, the binding sites perform deprotonation, yielding more negatively charged ligands, followed by an enhancement of adsorption capacity for La(III) and Y(III). From another perspective, other dissociation equilibria and anion concentration such as hydroxyl ions are increased at alkaline $\mathrm{pH}$ (6.0 and above the pKa). Consequently, the elements lanthanum and yttrium probably present in the form of hydroxyl complexes, changing their species into $[\mathrm{M}(\mathrm{OH})]_{n}{ }^{x-}[33]$. In that case, the adsorption for $\mathrm{La}(\mathrm{III})$ and Y(III) onto OP will be degraded. Combining with the FTIR observation of $\mathrm{OP}$, ion exchange and electrostatic interactions exist in the adsorption process, and the potential functional groups such as the $\mathrm{O}-\mathrm{H}, \mathrm{C}=\mathrm{O}$, and $\mathrm{C}-\mathrm{O}$ groups assume the main responsibility for binding $\mathrm{La}(\mathrm{III})$ and Y(III) ions [30].

3.2.2. Effect of Adsorbent Dosage. Figure 5 shows that the adsorption rate of $\mathrm{La}(\mathrm{III})$ and Y(III) increases as the dosage equally increases. This trend is attributed to increasing adsorbent particles at fixed concentrations, sufficient amounts of active sites, and available cites around rare earth cations together with larger specific surface area, resulting in stronger cation-adsorbent interactions [17]. The sharp decrease of the $\Delta y$ value ( $\Delta y$ is the slope divided by the adsorption rates of adjacent dosages) denotes that La(III) and Y(III) are chiefly adsorbed through monolayer swift contact to the filling and absorption. Given that the aggregation of adsorption sites, the total effective site area on the adsorbent surface decreases. Subsequently, due to the free sites are completely occupied, the ions further seek the adsorption sites inside the particles, which involves the induction of functional groups. The phase indicates that the physisorption of the diffusion step is a dominant role [36].

3.2.3. Effect of Temperature. As indicated from the Figure 6, the adsorption process undergoing two stages as the 


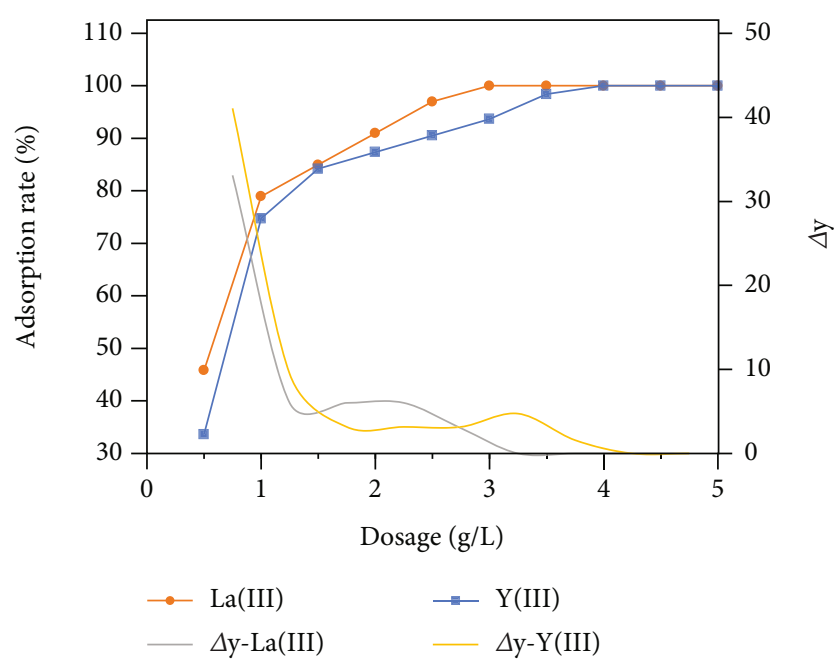

FIGURE 5: Effect of dosage on the adsorption of La(III) and Y(III) by OP (room temperature, $C_{0}=32 \mathrm{mg} / \mathrm{L}, V=100 \mathrm{~mL}, \mathrm{pH}=6, t=2 \mathrm{~h}$ ).

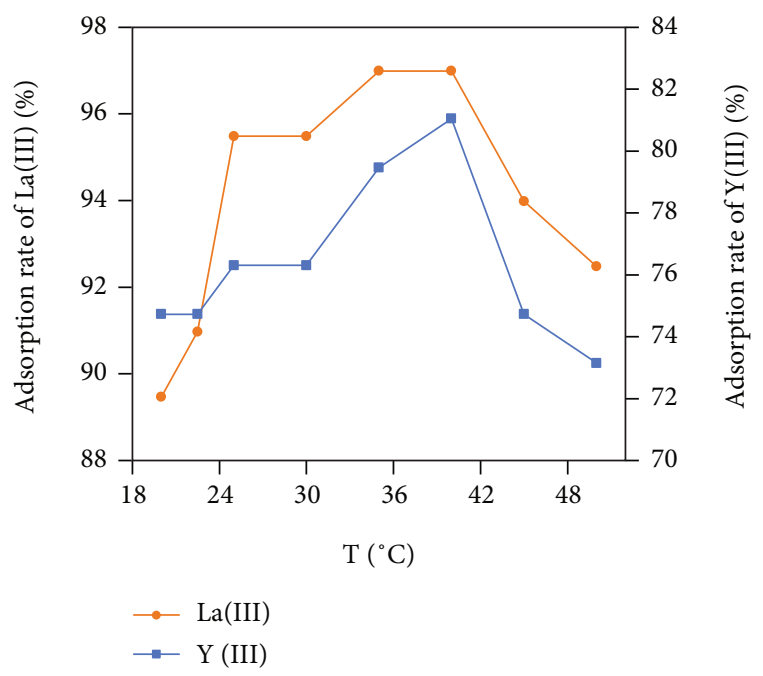

FIgURE 6: Effect of temperature on the adsorption of La(III) and Y(III) by OP $\left(C_{0}=32 \mathrm{mg} / \mathrm{L}, S / L=0.15 \mathrm{~g} / 100 \mathrm{~mL}, \mathrm{pH}=6\right)$.

temperature continues to go up. The first one is growth of the adsorption rate, reaching a maximum about $40^{\circ} \mathrm{C}$ with $95.49 \%$ and $76.31 \%$ for $\mathrm{La}(\mathrm{III})$ and $\mathrm{Y}(\mathrm{III})$ by OP, respectively. The higher adsorption rate results from the rising temperature generates driving force to boost the flowability of granules and molecules, thereby facilitating contact between ions and active site of OP [37]. Then, the rates drop sharply in the second stage demonstrates that the process is endothermic and spontaneous [38]. Explicably, overtemperature has the potential to destroy the properties of $\mathrm{OP}$ and destabilize rare earth cations, which subdue the positive reaction of adsorption.

3.2.4. Effect of Contact Time. Figure 7 shows that the adsorption was preliminarily faster within $15 \mathrm{~min}$, the remaining adsorption sites are unemployed as a result of inadequate contact time. Whereafter, the adsorption rate becomes sluggish and achieves adsorption equilibrium at about $30 \mathrm{~min}$.

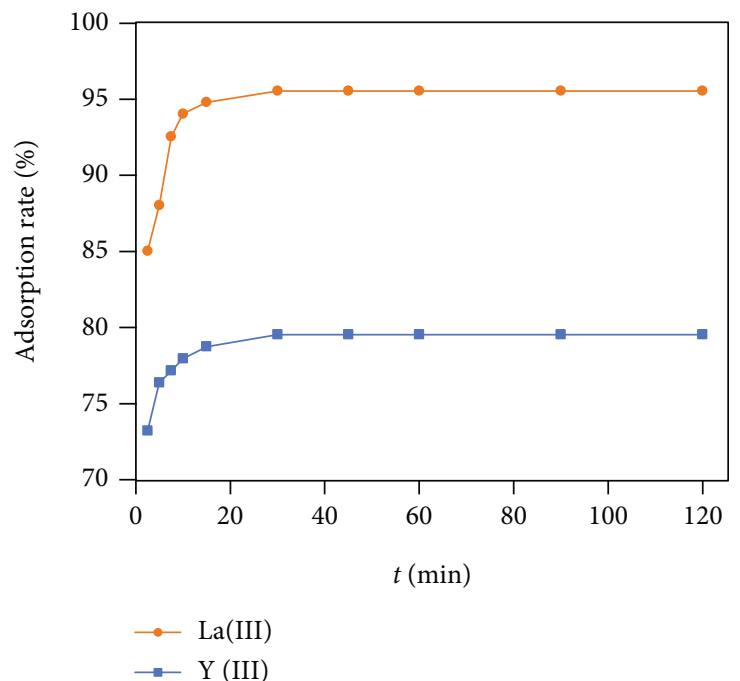

FIGURE 7: Effect of time on the adsorption of La(III) and Y(III) by OP (room temperature, $C_{0}=32 \mathrm{mg} / \mathrm{L}, S / L=0.15 \mathrm{~g} / 100 \mathrm{~mL}, \mathrm{pH}=6$ ).

This trend means that the available sites are basically occupied, $\mathrm{La}(\mathrm{III})$ and $\mathrm{Y}(\mathrm{III})$ progressive enter the micropores of OP, causing a step-down in adsorption velocity owing to the mass transfer resistance on the OP inner wall. This is because the adsorption rate depends on the presence of empty adsorption sites and a high gradient concentration of solute [33]. Prior to the dynamic equilibrium, the OP surface endows with abundant exchangeable sites and porous domains of the adsorbent, which have greater accessibility for the ion binding. As the reaction proceeding, adsorption rates reach the maximum and then remain stable, which indicates that the $\mathrm{OP}$ adsorption tends to be saturated.

3.2.5. Effect of Initial Concentration. Further analyses include a set of optimum dosage experiments $(\mathrm{La}(\mathrm{III})=2 \mathrm{~g} / \mathrm{L}$ and $\mathrm{Y}(\mathrm{III})=3 \mathrm{~g} / \mathrm{L})$ to verify the influence of the initial concentration for OP adsorption performance. Results presented in Figure 8 , the adsorption efficiency of $\mathrm{La}(\mathrm{III})$ and $\mathrm{Y}$ (III) declines near linearly from $100 \%$ to $44.64 \%$ and $36.81 \%$ by increasing the initial concentration. The rapid saturation of active sites cannot meet the growing demand of increasing ion adsorption, thereby limiting the interaction between ions and adsorbent. However, Figure 8(b) reveals that the increment of rare earth ions augmented the driving force for transporting themselves to fully use contact point of adsorbed particles.

By contrast, the adsorption rate of the optimum dosage groups $(\mathrm{La}(\mathrm{III})=2 \mathrm{~g} / \mathrm{L}$ and $\mathrm{Y}(\mathrm{III})=3 \mathrm{~g} / \mathrm{L})$ is higher than $1.5 \mathrm{~g} / \mathrm{L}$ groups and shows a more gradual downward trend. This phenomenon is explained by the fact that larger specific surface area contains more exchangeable sites with greater metal binding availability [33]. Therefore, appropriate dosages and concentration allow full access to rare earth cations and adsorbents to enhance their interaction.

3.3. Adsorption Isotherm. The equilibrium behavior of sorbents can be elucidated by isothermal adsorption models [30]. Langmuir, Freundlich, and Dubinin-Radushkevich 


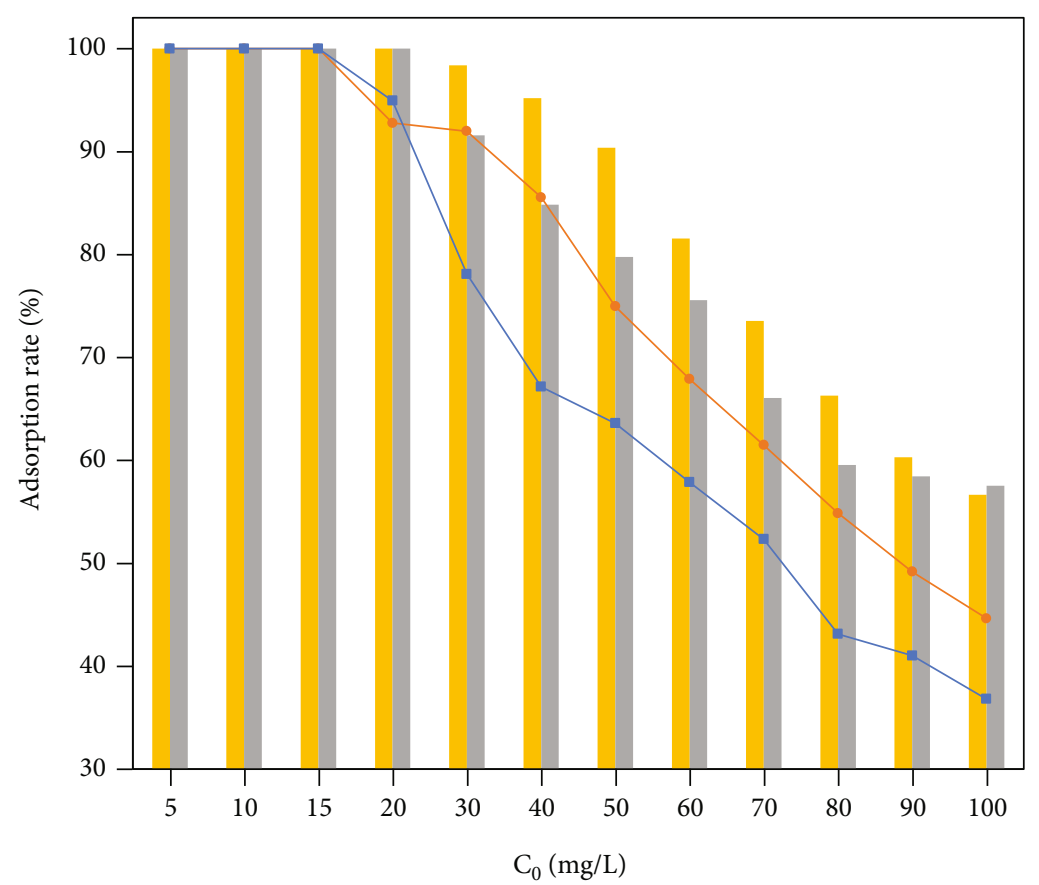

(a)

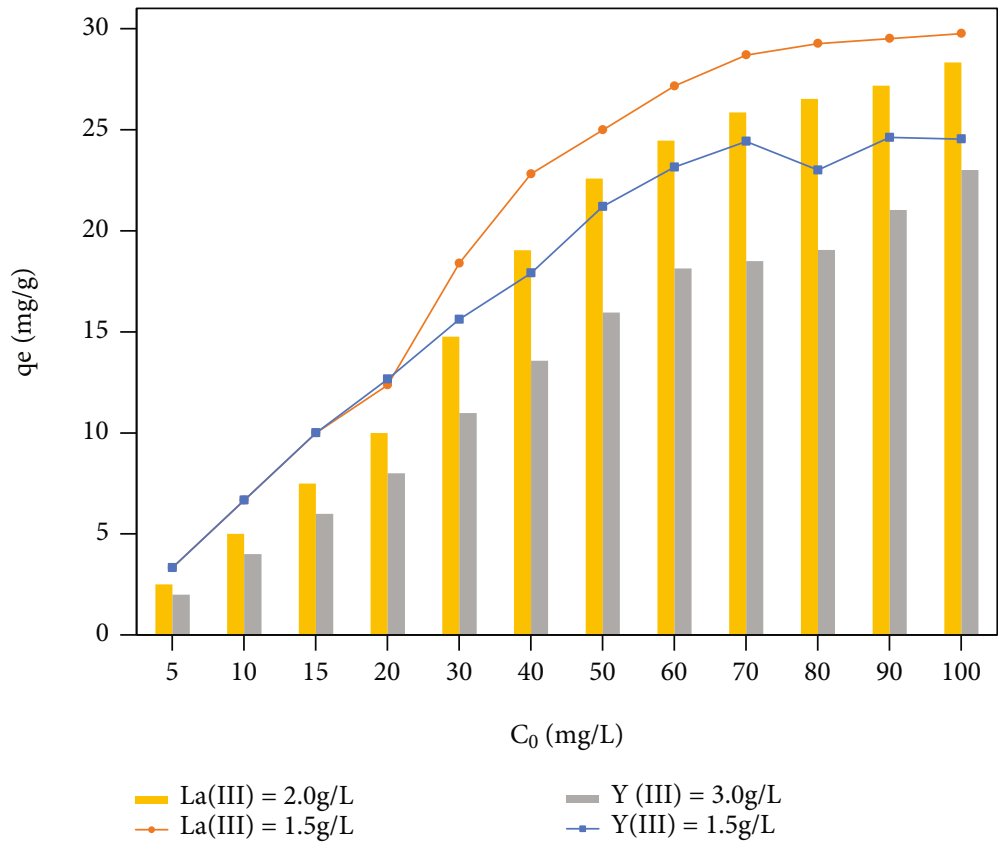

(b)

FIGURE 8: Effect of initial concentration on the adsorption of La(III) and Y(III) onto OP (room temperature, $t=2 \mathrm{~h}, V=100 \mathrm{~mL}, \mathrm{pH}=6$ ).

(D-R) models are utilized to fit the experimental data (Figure 9). These models describe the adsorption property of adsorbents. One is that the surface may exist as a homogeneous or heterogeneous system; the other is monolayer (single surface contact) or multilayer form (readsorption caused by the adsorption force field). In addition, information concerning the energy distribution of active sites and interactions between adsorbed molecules at the solid-liquid interface is obtained $[18,39]$.
Generally, the Langmuir isotherm assumes monolayer coverage of the adsorbent surface [40]:

$$
\frac{C_{\mathrm{e}}}{q_{\mathrm{e}}}=\frac{C_{\mathrm{e}}}{q_{\max }}+\frac{1}{q_{\max } K_{\mathrm{L}}},
$$

where $q_{\max }(\mathrm{mg} / \mathrm{g})$ represents the maximum monolayer adsorption capacity and $K_{\mathrm{L}}(\mathrm{L} / \mathrm{mg})$ is the Langmuir constant 


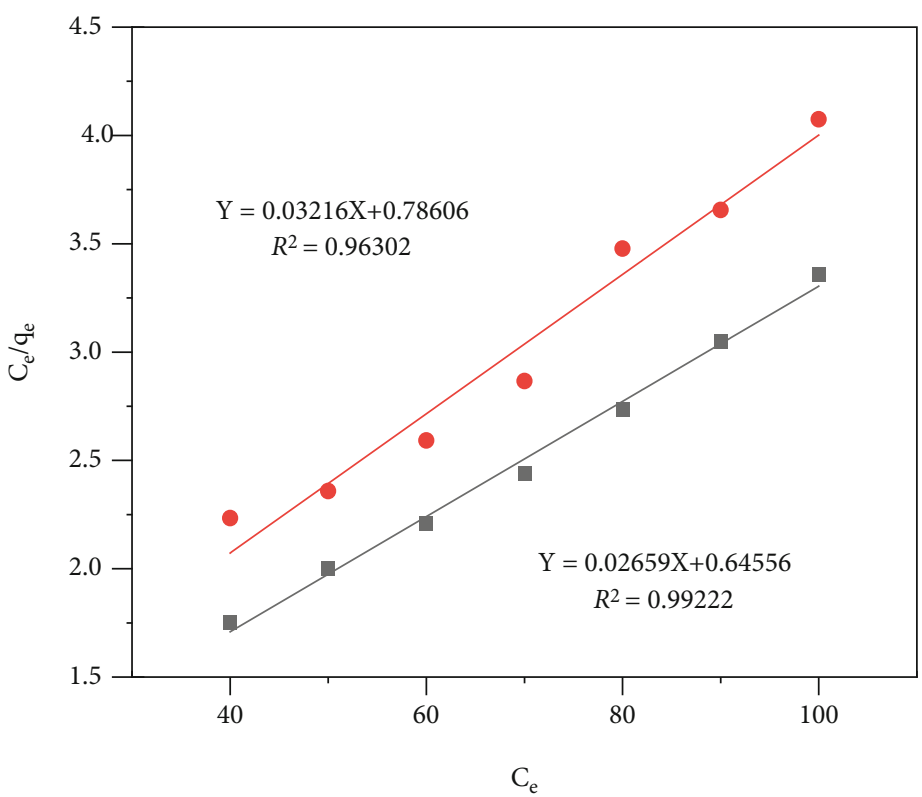

(a)

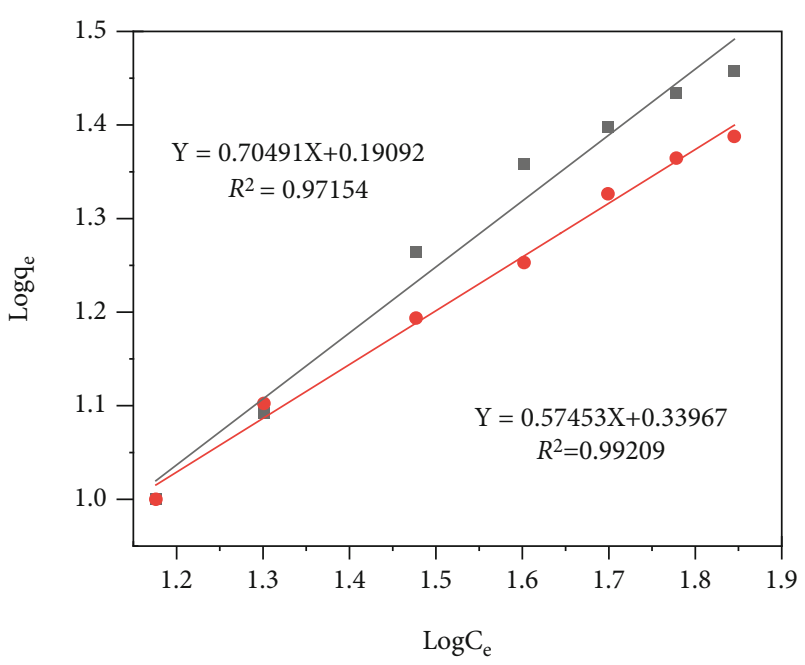

(b)

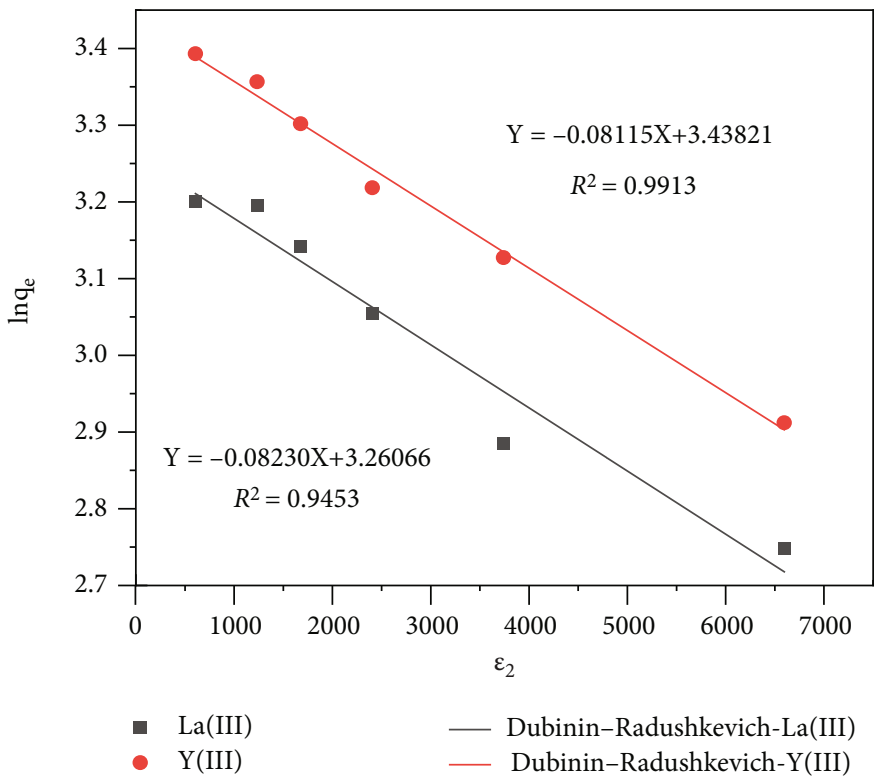

(c)

FIGURE 9: (a) Langmuir, (b) Freundlich, and (c) D-R isotherm plots for adsorption of La(III) and Y(III) onto OP.

related to adsorption energy. A linear plot of $C_{\mathrm{e}} / q_{\mathrm{e}}$ versus $C_{\mathrm{e}}$ is obtained for the adsorbent in Figure 9(a). The monolayer adsorption properties can be confirmed by the dimensionless separation factor $\left(R_{\mathrm{L}}\right)$ :

$$
R_{\mathrm{L}}=\frac{1}{1+K_{\mathrm{L}} C_{0}},
$$

where $C_{0}(\mathrm{mg} / \mathrm{L})$ is the initial ion concentration in the solution and the values of $R_{\mathrm{L}}$ lies between 0 and 1 , which implies that it is a favorable adsorption, unfavorable when $R_{\mathrm{L}}>1$ and irreversible when $R_{\mathrm{L}}=0$ [29].
The Freundlich isotherm assumes multilayer adsorption and a heterogeneous adsorbent surface [35]:

$$
\log q_{\mathrm{e}}=\log K_{\mathrm{F}}+\frac{1}{n} \log C_{\mathrm{e}}
$$

where $K_{\mathrm{F}}\left((\mathrm{mg} / \mathrm{g}) \cdot(\mathrm{L} / \mathrm{mg})^{1 / \mathrm{n}}\right)$ is the Freundlich constants and $n$ is the heterogeneity factor that relates to the adsorption capacity and intensity; they can be evaluated from the slope and intercept of the linear plot of $\log q_{\mathrm{e}}$ versus $\log C_{\mathrm{e}}$ in Figure 9(b).

The D- $\mathrm{R}$ model describes the adsorption mechanism that does not assume a homogenous surface or constant 
adsorption potential [41], which conduce to the explanation regarding homogeneous and heterogeneous adsorption surfaces. The linear plot representation of the D-R equation is defined as

$$
\ln q_{\mathrm{e}}=\ln q_{\mathrm{m}}-\beta \varepsilon^{2}
$$

where $q_{\mathrm{m}}(\mathrm{mg} / \mathrm{g})$ signifies the saturation adsorption capacity and $\varepsilon$ stands for Polanyi potential and is equal to

$$
\varepsilon=R T \ln \left(1+\frac{1}{C_{\mathrm{e}}}\right)
$$

The universal gas constant is given as $R(8.314 \mathrm{~J} /(\mathrm{mol} \cdot \mathrm{K}))$ and $T$ is temperature $(\mathrm{K})$. while $\left.\beta\left(\mathrm{mol}^{2} / \mathrm{kJ}\right)^{2}\right)$ stands for the adsorption free energy. The mean free energy of adsorption, $E(\mathrm{~kJ} / \mathrm{mol})$, can be calculated from $\beta$ :

$$
E=\frac{1}{\sqrt{-2 \beta}}
$$

where $E(\mathrm{~kJ} / \mathrm{mol})$ can provide prediction about the mechanism of adsorption [30]; when the $E$ value lies between 8 and $16 \mathrm{~kJ} / \mathrm{mol}$, it is a chemical ion-exchange process, but when $E$ is less than $8 \mathrm{~kJ} / \mathrm{mol}$ suggests a physical adsorption process $[30,35]$.

In this study, the best fitting results among the isothermal models are determined by applying the SSE and EABS error functions [30]:

$$
\text { The Sum of Errors Squares }(\mathrm{SSE})=\sum_{i=1}^{n}\left(q_{e-\exp }-q_{e-\mathrm{cal}}\right)^{2} \text {, }
$$

The Sum of the Absolute Errors (EABS) $=\sum_{i=1}^{n}\left|q_{e-\exp }-q_{e-\mathrm{cal}}\right|$.

Relevant parameters on the experimental data of the La(III) and Y(III) adsorption are as given in Table 1, and Figure 9 shows the linear plots of isotherm models. The $R^{2}$ values taken by the three isothermal models for the two ions are great, which verifies that the three models can describe experimental data with good validity. Whereas, by comparing the SSE and EABS values of the three models, the Langmuir model has the smallest error, which suggests that it gives the most suitable description for the adsorption system on OP. Similar findings have also been mentioned by other literatures, the adsorption isothermal of OP in other metal ion solutions are more relevant to Langmuir model $[30,42]$, and removal of $\mathrm{La}(\mathrm{III})$ and $\mathrm{Y}(\mathrm{III})$ by some general adsorbents are also conformed with the Langmuir model [33, 38, 43].

According to the Langmuir mathematical equation, the maximum adsorption capacity of $\mathrm{La}(\mathrm{III})$ and $\mathrm{Y}$ (III) is estimated to be 37.6 and $31.1 \mathrm{mg} / \mathrm{g}$, respectively. The adsorption mode of $\mathrm{La}(\mathrm{III})$ and $\mathrm{Y}$ (III) onto the OP surface is predomi- nantly monolayer which provides a single site to attach each ion. Since the $R_{\mathrm{L}}<1$ for La(III) and Y(III), which indicates that the process has favorable adsorption conditions [30]. It can also be understood that OP has higher adsorption performance than $\mathrm{Y}(\mathrm{III})$ in the process of removing $\mathrm{La}(\mathrm{III})$ from the aqueous solution.

Although the Freundlich equation is an empirical one, the adequate description of adsorption data in a restricted concentration range is worthy of reference [40]. With the magnitude of $1 / n$ between 0.1 and 1.0, which implies that the adsorption process is feasible to separate ions from the aqueous solution with greater heterogeneous adsorption site and energy distribution $(n>1)$. D-R parameter, $E$ of La(III) and Y(III), is found to be 7.85 and $7.80 \mathrm{~kJ} / \mathrm{mol}$, since the value of $E$ is smaller than $8 \mathrm{~kJ} / \mathrm{mol}$; the adsorption mechanism is physical reaction in nature $[30,35]$.

3.4. Adsorption Kinetics Studies. The pseudofirst-order (Equation (11)) and pseudosecond-order (Equation (12)) are performed to investigate adsorption kinetics of $\mathrm{La}(\mathrm{III})$ and Y(III) onto OP.

$$
\begin{aligned}
\log \left(q_{\mathrm{e}}-q_{t}\right) & =\log q_{\mathrm{e}}-\frac{k_{1} t}{2.303}, \\
\frac{t}{q_{t}} & =\frac{1}{k_{2} q_{\mathrm{e}}^{2}}+\frac{t}{q_{\mathrm{e}}}, \\
H & =k_{2} q_{\mathrm{e}}^{2},
\end{aligned}
$$

where $q_{t}(\mathrm{mg} / \mathrm{g})$ is the adsorption amount at time $t$ and $k_{1}$ $(1 / \mathrm{min})$ and $k_{2}(\mathrm{~g} /(\mathrm{mg} \cdot \mathrm{min}))$ are the rate constants for the pseudofirst-order and pseudosecond-order, respectively; $k_{2}$ is further used to measure the adsorption capacity and initial adsorption rate constant $H$ (mg/(g.min)) (Equation (13)) [31].

The fitting parameters and the linear plot are depicted in Table 2 and Figure 10. It is observed from the results that biosorption kinetics of $\mathrm{La}(\mathrm{III})$ and $\mathrm{Y}$ (III) on OP are well contoured by the pseudosecond-order equation. Consequently, the adsorption process mainly acts as the ratecontrolling factor. On the other hand, the $q_{\mathrm{e}}$ values suggest that $\mathrm{La}$ (III) are adsorbed more sufficiently than Y(III). According to the previous conclusions, this is due to the weaker repulsion between $\mathrm{La}(\mathrm{III})$ and sorbents, facilitating the activities of the remaining adsorptive sites. The $H$ values show that the adsorption of Y(III) onto OP reach equilibrium slightly faster owing to the greater external diffusion rate of Y(III) couple with a small diameter [30].

3.5. Comparison of Various Adsorbents. Other untreated adsorbents for La(III) and Y(III) are presented in Table 3. The results exhibit better adsorption capacity of OP adsorbent compared to the leaf, shell, and bone waste. As expected, modification of materials has increased their adsorption efficiencies, whereas the assessment of adsorbent more to the point if efficiency, availability, reusability, and economic aspect are considered [30]. It is noteworthy that the unmodified wastes also have competitive sorption capacity. 
TABLE 1: Isotherm parameters for La(III) and Y(III) adsorption onto OP.

\begin{tabular}{|c|c|c|c|}
\hline Model & Parameter & $\mathrm{La}(\mathrm{III})$ & $\mathrm{Y}(\mathrm{III})$ \\
\hline$q_{\mathrm{m}}(\exp )$ & & 31.2634 & 27.6044 \\
\hline \multirow{6}{*}{ Langmuir } & $q_{\max }$ & 37.6081 & 31.0945 \\
\hline & $K_{\mathrm{L}}$ & 0.0412 & 0.0409 \\
\hline & $R_{\mathrm{L}}(5-100 \mathrm{mg} / \mathrm{L})$ & $0.8292-0.1954$ & $0.8302-0.1964$ \\
\hline & $R^{2}$ & 0.9922 & 0.9630 \\
\hline & SSE & 75.7625 & 22.7167 \\
\hline & EABS & 21.8587 & 14.5486 \\
\hline \multirow{5}{*}{ Freundlich } & $K_{\mathrm{F}}$ & 1.2104 & 1.4045 \\
\hline & $n$ & 1.4186 & 1.7406 \\
\hline & $R^{2}$ & 0.9715 & 0.9921 \\
\hline & SSE & 172.3507 & 398.9251 \\
\hline & EABS & 37.3225 & 62.5976 \\
\hline \multirow{6}{*}{ Dubinin-Radushkevich (D-R) } & $K_{\mathrm{D}-\mathrm{R}}$ & 0.00812 & 0.00823 \\
\hline & $q_{\mathrm{m}}$ & 31.1311 & 26.0667 \\
\hline & $E$ & 7.8493 & 7.7945 \\
\hline & $R^{2}$ & 0.9913 & 0.9453 \\
\hline & SSE & 97.3420 & 125.9459 \\
\hline & EABS & 20.8711 & 26.0753 \\
\hline
\end{tabular}

TAble 2: Parameters of kinetic models for adsorption of La(III) and Y(III) onto OP.

\begin{tabular}{|c|c|c|c|c|c|c|c|c|}
\hline \multirow{2}{*}{ Type } & \multirow{2}{*}{$q_{\mathrm{e}}(\exp )$} & \multicolumn{3}{|c|}{ Pseudofirst-order } & \multicolumn{4}{|c|}{ Pseudosecond-order } \\
\hline & & $K_{1}$ & $q_{\mathrm{e}}$ & $R^{2}$ & $K_{2}$ & $q_{\mathrm{e}}$ & $H$ & $R^{2}$ \\
\hline $\mathrm{La}(\mathrm{III})$ & 20.3705 & 0.2241 & 3.9251 & 0.9545 & 0.2100 & 20.4270 & 87.612 & 0.9999 \\
\hline Y (III) & 16.9524 & 0.1596 & 1.0562 & 0.9722 & 0.3213 & 16.9887 & 92.728 & 1.0000 \\
\hline
\end{tabular}

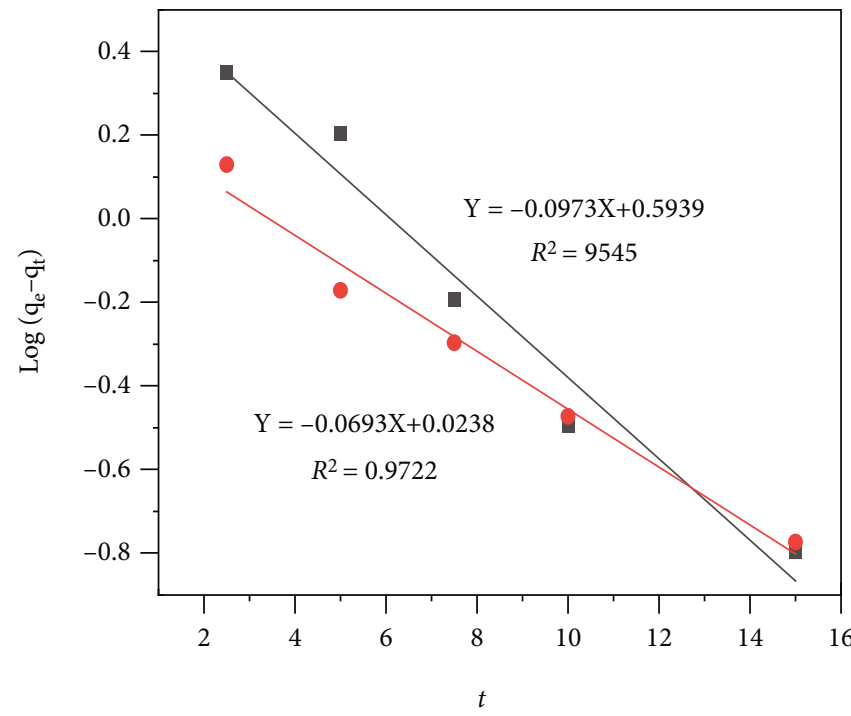

(a)

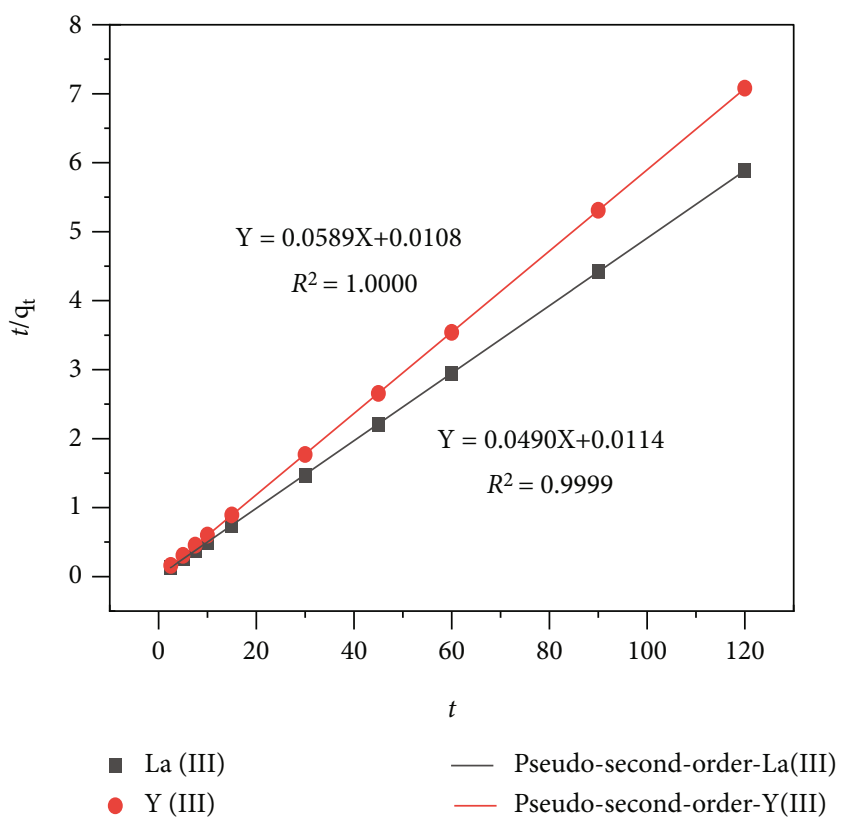

(b)

FIGURE 10: (a) Pseudofirst-order and (b) pseudosecond-order kinetic linear plots for adsorption of La(III) and Y(III) onto OP. 
TABLE 3: Comparison of orange peel adsorption capacity with other natural adsorbents for removal of La(III) and Y(III).

\begin{tabular}{|c|c|c|c|c|c|c|}
\hline Adsorbents & Metals & Particle size $(\mu \mathrm{m})$ & Concentration $(\mathrm{mg} / \mathrm{L})$ & Dose $(\mathrm{g} / \mathrm{L})$ & $q_{\mathrm{m}}(\mathrm{mg} / \mathrm{g})$ & References \\
\hline \multirow{2}{*}{ Orange peel } & $\mathrm{La}(\mathrm{III})$ & $125-150$ & 32 & 2 & 37.61 & \multirow{2}{*}{ Present study } \\
\hline & $\mathrm{Y}(\mathrm{III})$ & $125-150$ & 32 & 3 & 31.10 & \\
\hline \multirow{2}{*}{ Durian rind } & $\mathrm{La}(\mathrm{III})$ & $<500$ & $60-160$ & 2.5 & 71 & \multirow{2}{*}[33]{} \\
\hline & $\mathrm{Y}(\mathrm{III})$ & $<500$ & $60-160$ & 2.5 & 35 & \\
\hline Durian rind pectin & $\mathrm{La}(\mathrm{III})$ & $<500$ & 160 & 2.5 & 41.2 & {$[46]$} \\
\hline Pinus brutia leaf & $\mathrm{La}(\mathrm{III})$ & 125 & $25-300$ & 4 & 22.94 & {$[38]$} \\
\hline Platanus orientalis leaf & $\mathrm{La}(\mathrm{III})$ & 125 & $25-300$ & 4 & 28.65 & {$[47]$} \\
\hline Pleurotus ostreatus & $\mathrm{Y}(\mathrm{III})$ & $125-250$ & $50-350$ & 10 & 45.45 & {$[48]$} \\
\hline Pleurotus ostreatus & $\mathrm{La}(\mathrm{III})$ & $125-250$ & $50-350$ & 10 & 54.54 & [49] \\
\hline Orange peel & $\mathrm{La}(\mathrm{III})$ & $425-600$ & 250 & 2.5 & 125 & {$[50]$} \\
\hline Banana (peel, stem) & $\mathrm{Y}(\mathrm{III})$ & $250-800$ & $100-300$ & 1 & $<35,50$ & [39] \\
\hline Banana peel & $\mathrm{La}(\mathrm{III})$ & 65 & $20-200$ & 1 & 47.8 & {$[51]$} \\
\hline Grapefruit peel & $\mathrm{La}(\mathrm{III})$ & $<355$ & 20 & 2.5 & 171.20 & {$[52]$} \\
\hline Bone powder & $\mathrm{La}(\mathrm{III})$ & - & $5-500$ & 20 & 8.7 & {$[40]$} \\
\hline \multirow{2}{*}{ Pectin-chitosan composites } & $\mathrm{La}(\mathrm{III})$ & - & $10-180$ & 1 & 22 & \multirow{2}{*}[43]{} \\
\hline & $\mathrm{Y}(\mathrm{III})$ & - & $10-180$ & 1 & 23 & \\
\hline Buccinum tenuissimum shell & Lanthanides & $>600$ & $0.01-0.5$ & 2 & 6.2 & {$[53]$} \\
\hline
\end{tabular}

Among biosorbents, OP has attracted more attention. The $q_{\mathrm{m}}$ of the batch adsorption of $\mathrm{Cd}(\mathrm{II})$ by natural OP powder is $128.23 \mathrm{mg} / \mathrm{g}$ [30], the maximum adsorption capacity of cellulosic OP for $\mathrm{Cu}(\mathrm{II})$ is $63 \mathrm{mg} / \mathrm{g}$ [44], and the removal rate of $\mathrm{Cr}(\mathrm{VI})$ from wastewater with natural $\mathrm{OP}$ sorbent is higher than $95 \%$ [45]. It is agreed that this material has promising applications for effluent treatment.

\section{Conclusions}

The study herein indicates that OP as an economical adsorbent in practice is a good alternative for costly adsorbents. The adsorption rates are as high as $93.98 \%$ and $90.52 \%$ at a $\mathrm{pH}$ of 6.0 , temperature of $40^{\circ} \mathrm{C}$, and dosage of $\mathrm{La}$ (III) and $\mathrm{Y}$ (III) are $2 \mathrm{~g} / \mathrm{L}$ and $3 \mathrm{~g} / \mathrm{L}$ in initial ion concentration of $32 \mathrm{mg} / \mathrm{L}$ with the contact time more than $30 \mathrm{~min}$.

The priority of adsorption equilibrium data fitting obeys this order: Langmuir > Dubinin-Radushkevich > Freundlich. The adsorption process is dominated by monolayer chemisorption. In addition, the adsorption kinetics of $\mathrm{La}$ (III) and Y(III) onto OP are preferable described by the pseudosecond-order model. The characterization results reveal that the metal ion adsorption onto OP is a spontaneous physical-chemical interaction, and the OP surface sites, porous domains, and functional groups are contributed to the adsorption mechanism. In accordance with the present study finding, natural OP presents a promising biosorbent for eliminating $\mathrm{La}(\mathrm{III})$ and $\mathrm{Y}$ (III) from the aqueous solution.

\section{Data Availability}

The data that support the findings of this study are available from the corresponding author (VS) upon reasonable request.

\section{Conflicts of Interest}

The authors declared that there is no conflict of interest.

\section{Acknowledgments}

The authors gratefully acknowledge the financial support from the National Natural Science Foundation of China (51964014) and the Program of Science and Technology Research, Education Department of Jiangxi Province (GJJ200814).

\section{References}

[1] Y. F. Xiao, Y. Y. Chen, Z. Y. Feng et al., "Leaching characteristics of ion-adsorption type rare earths ore with magnesium sulfate," Transactions of Nonferrous Metals Society of China, vol. 25, no. 11, pp. 3784-3790, 2015.

[2] Z. Q. Guo, K. Zhao, J. F. Jin, W. Yuan, and C. Liang, "Problems facing ion adsorption type rare earth exploitation and research progresses on green extraction," Chemical Industry and Engineering Progress, vol. 38, no. 7, pp. 3425-3433, 2019.

[3] H. F. Zhan, H. S. Wang, Y. Pan, H. H. Sun, and Z. W. Liu, "Measurement and analysis of ion-type rare earth mine wastewater," Journal of the Chinese Society of Rare Earths, vol. 38, no. 4, pp. 550-556, 2020.

[4] K. Binnemans, P. T. Jones, T. Müller, and L. Yurramendi, "Rare earths and the balance problem: how to deal with changing markets?," Journal of Sustainable Metallurgy, vol. 4, pp. 126-146, 2018.

[5] G. C. Han, J. Y. Ning, Z. Yu et al., "Hazard assessment of the effects of rare earth element lanthanum on health," Journal of Toxicology, vol. 33, no. 6, 443 pages, 2019.

[6] D. Das, S. Jaya, and N. Das, "Recovery of lanthanum (III) from aqueous solution using biosorbents of plant and animal origin: batch and column studies," Minerals Engineering, vol. 69, pp. 40-56, 2014. 
[7] I. Anastopoulos, A. Bhatnagar, and E. C. Lima, "Adsorption of rare earth metals: a review of recent literature," Journal of Molecular Liquids, vol. 221, pp. 954-962, 2016.

[8] X. Gao, L. Jiang, Y. Mao, B. Yao, and P. Jiang, "Progress, challenges, and perspectives of bioleaching for recovering heavy metals from mine tailings," Adsorption Science and Technology, vol. 2021, article 9941979, 13 pages, 2021.

[9] V. S. Munagapati, J. C. Wen, C. L. Pan, Y. Gutha, and J. H. Wen, "Enhanced adsorption performance of reactive red 120 azo dye from aqueous solution using quaternary amine modified orange peel powder," Journal of Molecular Liquids, vol. 285, no. 4, pp. 375-385, 2019.

[10] A. el Nemr, R. M. Aboughaly, A. el Sikaily, S. Ragab, M. S. Masoud, and M. S. Ramadan, "Microporous nano-activated carbon type I derived from orange peel and its application for $\mathrm{Cr}(\mathrm{VI})$ removal from aquatic environment," Biomass Conversion and Biorefinery, vol. 1, pp. 1-19, 2020.

[11] I. C. Afolabi, S. I. Popoola, and O. S. Bello, "Modeling pseudosecond-order kinetics of orange peel-paracetamol adsorption process using artificial neural network," Chemometrics and Intelligent Laboratory Systems, vol. 203, p. 104053, 2020.

[12] B. P. Mora, F. A. Bertoni, M. F. Mangiameli, J. C. González, and S. E. Bellú, "Batch and fixed-bed column studies of selenite removal from contaminated water by orange peel-based sorbent," Water Science and Engineering, vol. 13, no. 4, pp. 307316, 2020.

[13] V. S. Munagapati and D. S. Kim, "Adsorption of anionic azo dye Congo Red from aqueous solution by Cationic Modified Orange Peel Powder," Journal of Molecular Liquids, vol. 220, pp. 540-548, 2016.

[14] M. Salman, M. Athar, and U. Farooq, "Biosorption of heavy metals from aqueous solutions using indigenous and modified lignocellulosic materials," Reviews in Environmental Science and Biotechnology, vol. 14, pp. 211-228, 2015.

[15] N. Das and D. Das, "Recovery of rare earth metals through biosorption: an overview," Journal of Rare Earths, vol. 31, no. 10, pp. 933-943, 2013.

[16] R. M. Naik, "Relationship between the Freundlich adsorption constants $\mathrm{K}$ and $1 / \mathrm{N}$ hydrophobic adsorption," Indian Journal of Chemical Technology, vol. 25, pp. 300-305, 2018.

[17] A. Pandiarajan, R. Kamaraj, S. Vasudevan, and S. Vasudevan, "OPAC (orange peel activated carbon) derived from waste orange peel for the adsorption of chlorophenoxyacetic acid herbicides from water: adsorption isotherm, kinetic modelling and thermodynamic studies," Bioresource Technology, vol. 261, pp. 329-341, 2018.

[18] C. Tejada-Tovar, A. Herrera-Barros, A. Villabona-Ortíz, Á. González-Delgado, and J. Núñez-Zarur, "Hexavalent chromium adsorption from aqueous solution using orange peel modified with calcium chloride: equilibrium and kinetics study," Indian Journal of Science and Technology, vol. 11, no. 17, pp. 1-10, 2018.

[19] C. Zhang, X. Zhou, and F. Gao, "Preparation of orange peel loaded Zn/Al-HT and its adsorption for $\mathrm{Cr}(\mathrm{VI})$ in water," IOP Conference Series: Earth and Environmental Science, vol. 687, no. 1, p. 012073, 2021.

[20] M. T. Amin, A. A. Alazba, and M. Shafiq, "Application of the biochar derived from orange peel for effective biosorption of copper and cadmium in batch studies: isotherm models and kinetic studies," Arabian Journal of Geosciences, vol. 12, no. 2, pp. 46-58, 2019.
[21] C. Tejada-Tovar, Á. González-Delgado, and A. VillabonaOrtíz, "Adsorption kinetics of orange peel biosorbents for $\mathrm{Cr}(\mathrm{VI})$ uptake from water," Contemporary Engineering Sciences, vol. 11, no. 24, pp. 1185-1193, 2018.

[22] S. Pavithra, G. Thandapani, S. S et al., "Batch adsorption studies on surface tailored chitosan/orange peel hydrogel composite for the removal of $\mathrm{Cr}(\mathrm{VI})$ and $\mathrm{Cu}(\mathrm{II})$ ions from synthetic wastewater," Chemosphere, vol. 271, no. 12, p. 129415, 2021.

[23] L. X. Wang, X. T. Zhou, and Z. Q. Luo, "Research Progress of the properties and mechanism of heavy metal $\mathrm{Pb}^{2+}$ absorbed by agricultural and forestry waste in wastewater," Materials Reports, vol. 34, no. 17, pp. 119-127, 2020.

[24] N. C. Feng and X. Y. Guo, "Characterization of adsorptive capacity and mechanisms on adsorption of copper, lead and zinc by modified orange peel," Transactions of Nonferrous Metals Society of China, vol. 22, pp. 1224-1231, 2012.

[25] N. C. Feng, X. Y. Guo, and S. Liang, "Adsorption study of copper(II) by chemically modified orange peel," Journal of Hazardous Materials, vol. 164, no. 2-3, pp. 1286-1292, 2009.

[26] X. F. Zhang, J. X. Xiang, J. Q. Tian, and Y. Xie, "Preparation of activated carbons from waste cCitrus dregs by. $\mathrm{Na}_{2} \mathrm{CO}_{3}, \mathrm{~K}_{2} \mathrm{CO}_{3}$ and $\mathrm{KOH}$ and performance analysis," Chemical Reagents, vol. 43, no. 3, pp. 274-279, 2021.

[27] Z. G. Xie, F. Y. Ji, X. M. Qiu, and H. Huang, "Preparation and characterization of mesoporous activated carbon from orange peel," Journal of Functional Materials, vol. 40, no. 4, pp. 645649, 2009.

[28] Z. S. Birungi and E. Chirwa, "The kinetics of uptake and recovery of lanthanum using freshwater algae as biosorbents: comparative analysis," Bioresource Technology, vol. 160, no. 5, pp. 43-51, 2014.

[29] A. A. Ayalew and T. A. Aragaw, "Utilization of treated coffee husk as low-cost bio-sorbent for adsorption of methylene blue," Adsorption Science and Technology, vol. 38, no. 5-6, pp. 205-222, 2020.

[30] T. F. Akinhanmi, E. A. Ofudje, A. I. Adeogun, P. Aina, and I. M. Joseph, "Orange peel as low-cost adsorbent in the elimination of $\mathrm{Cd}(\mathrm{II})$ ion: kinetics, isotherm, thermodynamic and optimization evaluations," Bioresources and Bioprocessing, vol. 7, no. 1, pp. 1-16, 2020.

[31] C. Pathirana, A. M. Ziyath, K. B. S. N. Jinadasa, P. Egodawatta, and A. Goonetilleke, "Mathematical modelling of the influence of physico-chemical properties on heavy metal adsorption by biosorbents," Chemosphere, vol. 255, p. 126965, 2020.

[32] I. A. Altameemi and M. A. Thuraya, "Removal of manganese $\left(\mathrm{Mn}^{2+}\right)$ from aqueous solution by low-cost adsorbents and study the adsorption thermodynamics and kinetics," Journal of Physics: Conference Series, vol. 1773, no. 1, p. 012038, 2021.

[33] E. Kusrini, A. Usman, F. A. Sani, L. D. Wilson, and M. A. A. Abdullah, "Simultaneous adsorption of lanthanum and yttrium from aqueous solution by durian rind biosorbent," Environmental Monitoring and Assessment, vol. 191, no. 8, pp. 1-8, 2019.

[34] B. Thomas, E. P. Shilpa, and L. K. Alexander, "Role of functional groups and morphology on the $\mathrm{pH}$-dependent adsorption of a cationic dye using banana peel, orange peel, and neem leaf bio-adsorbents," Emergent Materials, vol. 35, pp. 1-9, 2021.

[35] A. A. Alghamdi, A. B. al-Odayni, N. Abduh, S. A. Alramadhan, M. T. Aljboar, and W. S. Saeed, "Adsorptive performance of polypyrrole-based $\mathrm{KOH}$-activated carbon for the cationic dye 
crystal violet: kinetic and equilibrium studies," Adsorption Science and Technology, vol. 2021, article 5527594, 11 pages, 2021.

[36] C. Pathirana, A. M. Ziyath, K. B. S. N. Jinadasa, P. Egodawatta, S. Sarina, and A. Goonetilleke, "Quantifying the influence of surface physico-chemical properties of biosorbents on heavy metal adsorption," Chemosphere, vol. 234, pp. 488-495, 2019.

[37] M. B. Amar, K. Walha, and V. Salvadó, "Valorisation of pine cone as an efficient biosorbent for the removal of $\mathrm{Pb}(\mathrm{II})$, $\mathrm{Cd}(\mathrm{II}), \mathrm{Cu}(\mathrm{II})$, and $\mathrm{Cr}(\mathrm{VI})$," Adsorption Science and Technology, vol. 12, p. 12, 2021.

[38] C. Kütahyali, S. Sert, B. Çetinkaya, S. Inan, and M. Eral, "Factors affecting lanthanum and cerium biosorption onPinus brutiaLeaf powder," Separation Science and Technology, vol. 45, no. 10, pp. 1456-1462, 2010.

[39] B. Lapo, J. J. Bou, J. Hoyo et al., “A potential lignocellulosic biomass based on banana waste for critical rare earths recovery from aqueous solutions," Environmental Pollution, vol. 264, p. 114409, 2020.

[40] M. Butnariu, P. Negrea, L. Lupa et al., "Remediation of rare earth element pollutants by sorption process using organic natural sorbents," International Journal of Environmental Research and Public Health, vol. 12, no. 9, pp. 11278-11287, 2015.

[41] A. Daouda, A. T. Honorine, N. G. Bertrand, D. Richard, and R. Domga, "Adsorption of Rhodamine B onto Orange Peel Powder," American Journal of Chemistry, vol. 9, no. 5, pp. 142-149, 2019.

[42] L. Salisu and M. B. Ibrahim, "Analysis of some sorption isotherms for the removal of $\mathrm{Ni}^{2+}, \mathrm{Pb}^{2+}$ and $\mathrm{Cu}^{2+}$ using orange peel adsorbent," Bayero Journal of Pure and Applied Sciences, vol. 10, no. 1, pp. 414-417, 2017.

[43] D. Kong, E. Kusrini, and L. D. Wilson, "Binary pectin-chitosan composites for the uptake of lanthanum and yttrium species in aqueous media," Micromachines, vol. 12, no. 5, p. 478, 2021.

[44] S. Guiza, "Biosorption of heavy metal from aqueous solution using cellulosic waste orange peel," Ecological Engineering, vol. 99, pp. 134-140, 2017.

[45] T. J. Jisha, C. H. Lubna, and V. Habeeba, "Removal of Cr (VI) using orange peel as an adsorbent," IJARIIE, vol. 3, no. 4, pp. 276-283, 2017.

[46] E. Kusrini, W. Wicaksono, C. Gunawan, N. Z. A. Daud, and A. Usman, "Kinetics, mechanism, and thermodynamics of lanthanum adsorption on pectin extracted from durian rind," Journal of Environmental Chemical Engineering, vol. 6, no. 5, pp. 6580-6588, 2018.

[47] Ş. Sert, C. Kütahyali, S. İnan, Z. Talip, B. Çetinkaya, and M. Eral, "Biosorption of lanthanum and cerium from aqueous solutions by _Platanus orientalis_leaf powder," Hydrometallurgy, vol. 90, no. 1, pp. 13-18, 2008.

[48] S. S. Hussien and O. A. Desouky, "Biosorption studies on yttrium using low cost pretreated biomass of Pleurotus ostreatus," International conference on radiation research and applied science, vol. 10, pp. 139-150, 2014.

[49] S. S. Hussien, "Biosorption of lanthanum from aqueous solution using Pleurotus ostreatus basidiocarps," International Journal of Biotechnology, vol. 2, no. 3, pp. 26-36, 2014.

[50] C. Varshini and N. Das, "Relevant approach to assess the performance of biowaste materials for the recovery of lanthanum (III) from aqueous medium," Research Journal of Pharmaceutical, Biological and Chemical Sciences, vol. 5, no. 6, pp. 88-94, 2014.
[51] O. A. Oyewo, M. S. Onyango, and C. Wolkersdorfer, "Lanthanides removal from mine water using banana peels nanosorbent," International journal of Environmental Science and Technology, vol. 15, no. 6, pp. 1265-1274, 2017.

[52] M. Torab-Mostaedi, M. Asadollahzadeh, A. Hemmati, and A. Khosravi, "Biosorption of lanthanum and cerium from aqueous solutions by grapefruit peel: equilibrium, kinetic and thermodynamic studies," Research on Chemical Intermediates, vol. 41, no. 2, pp. 559-573, 2015.

[53] Y. Koto, N. Kano, Y. Wang, N. Sakamoto, and H. Imaizumi, "Biosorption of lanthanides from aqueous solutions using pretreated Buccinum tenuissimum shell biomass," Bioinorganic Chemistry and Applications, vol. 2010, Article ID 804854, 10 pages, 2010. 